\title{
MOLECULAR SWITCH THAT CONTROLS THE FLUX OF LINOLEIC ACID INTO N-6 OR N-3 POLYUNSATURATED FATTY ACIDS IN MICROORGANISMS
}

\author{
${ }^{1}$ Mingxuan Wang, ${ }^{2}$ Jianxin Chen, ${ }^{1}$ Huaiyuan Zhang and ${ }^{1}$ Yuanda Song \\ ${ }^{1}$ State Key Laboratory of Food Science and Technology, Jiangnan University, Wuxi 214122, Jiangsu, China \\ ${ }^{2}$ School of Science, Changzhou Institute of Technology, Changzhou 213022, Jiangsu, China \\ Received 2014-06-30; Revised 2014-06-30; Accepted 2014-07-02

\begin{abstract}
Polyunsaturated Fatty Acids (PUFA) of the n-6 and n-3 series play important roles in nutrition. fatty acids as the major PUFAs and very few produce both. This differential production suggests that PUFAs metabolic pathway is strictly controlled in microorganisms. The major pathway of $n-6 / n-3$ faty acids

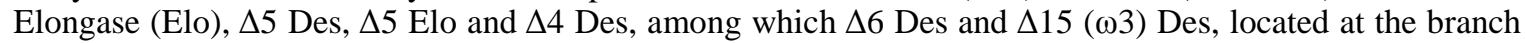
point of PUFAs metabolic pathways, are key regulators of the flux of linoleic acid (18:2 n-6) into either n-6 control the production of n-6/n-3 fatty acids. However the mechanism of the molecular switch is, so far, not clear. This review summarizes the recent advancement of the molecular base of the differentail production of n-6 or n-3 PUFAs in microorganisms.
\end{abstract} \\ Microorganisms are important sources of n-6 and n-3 fatty acids; however, most produce either n-6 or n-3 \\ biosynthesis in lower eukaryotes is composed of $\Delta 12$ Desaturase (Des), $\omega 3$ Des $(\Delta 15, \Delta 17), \Delta 6$ Des, $\Delta 6$ \\ or n-3 fatty acid metabolic pathways. These latter two enzymes work together as a molecular switch that
}

Keywords: Poly Unsaturated Fatty Acids (PUFAs), n-6 PUFAs, n-3 PUFAs, Metabolic Flux, Microorganisms

\section{INTRODUCTION}

Poly Unsaturated Fatty Acids (PUFAs) are straight chain fatty acids with chain lengths varying from $\mathrm{C} 18$ to $\mathrm{C} 22$ and more than two double bonds. Among these, $\mathrm{n}-6$ and $\mathrm{n}-3$ fatty acids are essential to human health and play important but different physiological roles. A balanced ratio of $n-6 / n-3$ fatty acids and the amount of n-3 fatty acids, is regarded as important factors for human health (Harris, 2006; Scott et al., 2007; Candela et al., 2011). However the ratio of $n-6 / n-$ 3 in current diet oils is commonly around 10:1 to $25: 1$, which is far from ideal, due to the fact that most of the traditional plant oils, such as soybean oil, sunflower oil, peanut oil, contains high-levels of n-6 fatty acid, linoleic acid (LA; 18:2 n-6)), with the exception of a few plant oils, such as Linum usitatissimum and Perilla frutescens, that contain very high amounts of n-3 fatty acid, Alpha-Linoleic Acid (ALA; 18:3 n-3). Furthermore, most plant species do not usually produce $\Delta 6$-desaturated fatty acids, with a few exceptions such as Boraginaceae, Oenothera spp. and Ribes spp. (Gunstone, 1992). In addition, some members of the Primulaceae family accumulate $\gamma$-linolenic acid (GLA; 18:3 n-6) and SteariDonic Acid (SDA; 18:4 n-3) (Sayanova et al., 1999; 2006). Primula species can produce either n-6 or n-3 $\Delta 6$-desaturated fatty acids (GLA or SDA) depending on the substrate preference of $\Delta 6$ Desaturase ( $\Delta 6$ Des) but the overall production of n-3 fatty acids is much higher than n-6 fatty acids suggesting a high activity of $\omega-3$ Desaturase ( $\omega-3$ Des) is present in these organisms (Sayanova et al., 1999; 2003; 2006). However, in general, higher plants does not produce PUFAs with carbon chain length beyond $\mathrm{C} 18$ and the few that do, do not produce fatty acids with more than two double bonds.

Corresponding Author: Yuanda Song, State Key Laboratory of Food Science and Technology, Jiangnan University, Wuxi 214122, Jiangsu, China and Jianxin Chen, School of Science, Changzhou Institute of Technology,

Changzhou 213022, Jiangsu, China 
Very long chain PUFAs (VL-PUFAs, with carbon chain length $\geqq 20$ ) commonly occur in many microorganisms including microalgae (Lenihan-Geels et al., 2013), filamentous fungi (Shimizu et al., 1988), marine protists Schizochytrium and Thraustochytrium (traditionally refered to marine fungi) (Nagano et al., 2011) and bacteria (Abd Elrazak et al., 2013). In microalgae and filamentous fungi, the biosynthetic pathway for PUFAs is the desaturase/elongase system, while in marine protsits, the desaturase/elongase system and Polyketide Synthase (PKS) both exist and in marine bacteria only PKS is available for PUFAs biosynthesis (Metz et al., 2001). Therefore in this review we focus on the regulation of PUFAs biosynthesis in microalgae and filamentous fungi. Most oleaginuous microorganisms, such as algae and a few fungi, produce oils with n-3 fatty acids as dominant PUFAs, some, such as the zygomycete fungi, produce oils with n-6 fatty acids as dominant PUFAs, only very few microorganisms can produce oils with both $n-3$ and n-6 fatty acids as major PUFAs. Therefore the production of different series of PUFAs is strictly regulated in each individual microorganism, suggesting that the metabolic flux of LA to n-6/n-3 fatty acids is controlled by endogeneous biosynthetic pathways which are regulated by either the property of the enzymes, such as their substrate preference, or environmental stimuli such as low temperature, which has been shown to induce n-3 fatty acid prodution (Shimizu et al., 1988). The main enzymes involved in the biosynthesis of n-6/n-3 PUFAs in eukaryotic microorganisms (both algae and fungi) are: $\Delta 12$ Des, $\omega-3$ $(\Delta 15, \Delta 17)$ Des, $\Delta 6$ Des, $\Delta 6$ Elo, $\Delta 5$ Des, $\Delta 5$ Elo and $\Delta 4$ Des (Pereira et al., 2003), as shown in Fig. 1.

During the synthesis of PUFAs, the precursor, oleic acid (18:1 n-9) is first converted to LA (18:2 n-6) by $\Delta 12$ Des which, in turn, is converted to ALA (18:3 n-3) by $\triangle 15$ Des. LA and ALA are further converted to Docosapentaenoic Acid (DPA, 22:5 n-6) and Docosahexaenoic Acid (DHA, 22:6 n-3), respectively, as the end products of the n-6/n-3 fatty acid pathways catalysed by $\Delta 6$ Des, $\Delta 6$ Elo, $\Delta 5$ Des, $\Delta 5$ Elo and $\Delta 4$ Des. Among these enzymes, $\Delta 6$ Des and $\omega-3$ Des (especially $\Delta 15$ Des), located at the branch point of $n-$ 6/n-3 fatty acid pathways, work together as a molecular switch that regulate the flux of LA into either n-6 or n-3 fatty acid pathway. $\omega-6$

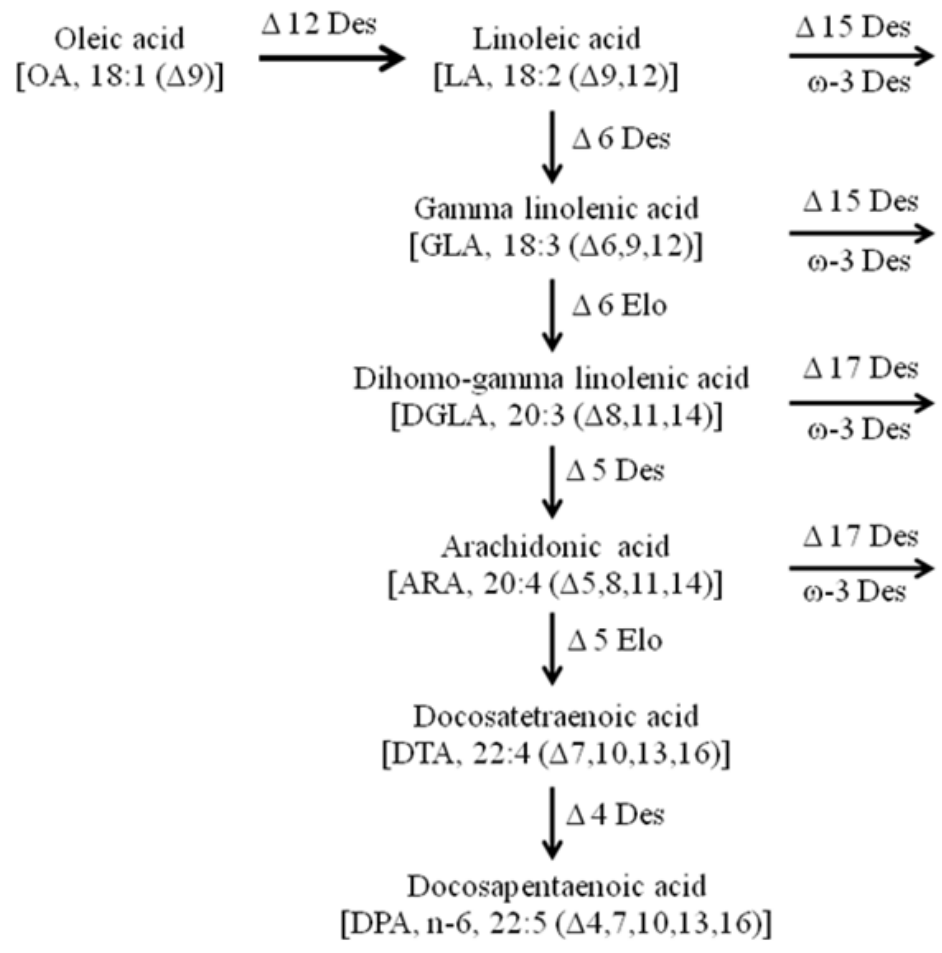

$\omega-3$

Alpha linolenic acid [ALA, 18:3 $(\Delta 9,12,15)]$

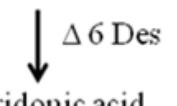

Stearidonic acid

[SDA, 18:4 $(\Delta 6,9,12,15)]$<smiles>CC[14CH2][14CH2]</smiles>

Eicosatetraenoic acid [ETA, 20:4 $(\Delta 8,11,14,17)]$<smiles>CC[AsH2]</smiles>

Eicosapentaenoic acid [EPA, 20:5 ( $\Delta 5,8,11,14,17)]$<smiles>CC[As]</smiles>

Docosapentaenoic acid [DPA, n-3, 22:5 $(\Delta 7,10,13,16,19)]$<smiles>CC[AsH][AsH2]</smiles>

Docosahexaenoic Acid [DHA, 22:6 $(\Delta 4,7,10,13,16,19)]$

Fig. 1. Main metabolic pathway of LA flux into n-6 or n-3 PUFAs in eukaryotic microorganisms 
In this article, we summarize the recent findings about n6/n-3 fatty acid production in microorganisms that contain both $\Delta 6$ Des and $\omega-3$ Des. We also give a summary of the biochemical characterization of $\Delta 6$ Des and $\omega-3$ Des and provide a rational correlation between the LA flux and the substrate preference and activity of the molecular switch.

\section{MICROORGANISMS THAT CONTAIN BOTH $\triangle 6$ DES AND $\Omega-3$ DES GENES}

Not all PUFAs-producing microorganisms with desaturase systems contain both $\Delta 6$ Des and $\omega-3$ Des genes. For example, the filamentous fungi Mucor circinelloides that produces significant amounts of GLA (Kennedy et al., 1993), but not ALA or SDA, has the $\Delta 6$ Des gene but not that coding for $\Delta 15(\omega-3)$ Des in its genome as revealed by genomic analysis (http://genome.jgi-psf.org/Mucci2/Mucci2.home.html).

In contrast, the green microalga, Chlamydomonas reinhardtii, that produces $80 \%$ of its total fatty acids as n-3 fatty acid ALA (18:3 n-6) has $\omega-3$ Des gene but not $\Delta 6$ Des gene in its genome (Nguyen et al., 2013). Neither of these microorganisms has both $\Delta 6$ Des and $\omega$ 3 Des and clearly no switching between the PUFA pathways is possible. Therefore, these and similar oleaginous microorganisms that only produce PUFAs of a single series will not be further discussed in this paper.

Although genomic sequences of many fungi and microalgae are available, the desaturases of those organisms have yet to be identified. Those organisms that have both $\Delta 6$ and $\omega-3$ Des, based on the PUFAs profile of the microorganisms, including some where molecular work has been carried out on their desaturases, are listed in Table 1. Most microorganisms that have both $\Delta 6$ Des and $\omega-3$ Des are filamentous fungi and microalgae. In general, yeast species have $\Delta 15(\omega-3)$ Des but not $\Delta 6$ Des in their genome; however, one yeast, Candida diddensiae, may have both $\Delta 6$ and $\omega-3$ Des based on its fatty acid profile (Rateldge, 1997). This, however, is from a single report and the constituent desaturases were not identified. Interestingly, cyanobacteria species show highly diversified desaturase systems (Dyal and Narine, 2005): Group 1 have only $\Delta 9$ Des and, as a consequence, they produce only monounsaturated fatty acids; group 2 have $\Delta 9$ Des, $\Delta 12$ Des and $\Delta 15(\omega-3)$ Des and, accordingly, these organisms can produce LA, that is further converted to n3 fatty acid ALA (18:3n-3); group 3 contain $\Delta 9$ Des, $\Delta 12$ Des and $\Delta 6$ Des and produce LA, that is further converted to GLA (18:3 n-6); group 4 contain $\Delta 9$ Des, $\Delta 12$ Des, $\Delta 15(\omega-3)$ Des and $\Delta 6$ Des, therefore the LA produced in this group of cyanobacteria can be converted into both n-6 GLA and n-3 ALA.

\section{MOLECULAR SWITCH OF MICROORGANISMS THAT PRODUCE N-6 FATTY ACIDS AS MAJOR LIPIDS}

Species belonging to the genus Mortierella can produce large amounts of Arachidonic Acid (ARA; 20:4 n-6) but very little Eicosapentaenoic Acid (EPA; 20:5 n3) (Murata and Wada, 1995). Mortierella alpina is currently used to produce ARA commercially. Genomic analysis has shown that this fungus contains $\Delta 15(\omega-3)$ Des, $\Delta 6$ Des, $\Delta 6$ Elo and $\Delta 5$ Des fatty acid desaturation/elongation systems for the production of series PUFAs (Wang et al., 2011). Although it contains a complete set of desaturase genes for the biosynthesis of both ARA (n-6) and EPA (n-3), at physiological growth temperatures, it produces ARA as the only major VLPUFA. This regulation of PUFA metabolic flux is partly due to the substrate specificity of the $\Delta 6$ Des Table 2, (Liu et al., 2011; Sakuradani and Shimizu, 2003; Sakuradani et al., 2005; Zhu et al., 2002) which prefers n-6 fatty acid LA to n-3 ALA as substrate and its $\omega-3$ Des must be repressed at physiological growth temperature (Shimizu et al., 1998). Although the $\omega-3$ Des have been cloned and biochemically studied in a few microorganisms Table 5, (Gellerman and Schlenk, 1979; Pereira et al., 2004; Sakamoto et al., 1994; Wada and Murata, 1990), its expression level in oleaginous microorganisms has not been determined so far. However over-expression of $\omega-3$ Des in Mt. alpina by genetic engineering increased the production of EPA from 5 to $35 \%$ of the total FAs and ARA decreased from 60 to $30 \%$ of total FAs, while the amount of total fatty acids did not change significantly (Ando et al., 2009). These results suggested that the $\Delta 6$ Des and $\omega-3$ Des work together as a switch, which is regulated by their substrate preference and activity, controlling the flux of LA into n-6 and/or n-3 fatty acid pathways. Furthermore, at low temperatures $\left(12-14^{\circ} \mathrm{C}\right)$ some species of $\mathrm{Mt}$. alpina can produce significant amount of EPA $(2 \% \mathrm{w} / \mathrm{w}$ of TFA for strain ATCC 32222; $15 \% \mathrm{w} / \mathrm{w}$ of TFA for strain IS-4). These results suggested that $\omega-3$ Des, which converts LA to ALA, is regulated by temperature. Whereas cold-induced expression of $\omega-3$ Des gene at mRNA level have been found in algae and many plants (Wada and Murata 1990; Shi et al., 2011; Zhang et al., 
2011; Takemura et al., 2012) and it is most sensitive to changes in temperature compared to other desaturases such as $\Delta 9, \Delta 12$ and $\Delta 6$ Des gene (Sakamoto et al., 1994). Therefore, it is suggested that $\omega-3$ Des gene in $M t$. alpina is repressed at physiological temperature of $25-28^{\circ} \mathrm{C}$, leading to flux of LA to ARA and at low temperature, it is induced, leading to the partial flux of LA to ALA, which is further metabolized to EPA.

Recent work has found that a phototrophic alga, Parietochloris incisa, can produce ARA up to $60 \%$ of the total FA, but with very little EPA Table 4, (Iskandarov et al., 2010), although the $\Delta 6$ Des of this organism can convert LA and ALA at similar activities. This suggests that its $\Delta 15$ or $\omega-3$ Des gene must be repressed at physiological temperatures, which resulting in the switch-off of LA flux to ALA and therefore leading to diminished flux of ALA to EPA. Similarly, other organisms such as Synechocystis sp. PCC 6803 and Conidiobolus obscurus that can produce more n- 6 fatty acids than n-3 fatty acids, even though their $\Delta 6$ Des works equally with either n-6 or n-3 fatty acid Table 3, (Reddy et al., 1993; Tan et al., 2011).

Pythium irregulare, is a rare example of a microorganism that can produce both n-6 ARA and n-3 EPA as its major PUFAs Table 4, (O'Brien et al., 1993; Hong et al., 2002). The $\Delta 6$ Des of this fungus can catalyze the desaturation of both LA and ALA at high conversion yields, albeit with slight substrate preference towards LA. These results indicate that a $\omega-3$ Des is actively expressed in this organism. Furthermore, the fungus produced much more EPA than ARA (1.4-fold increase) when grow at low temperature state, likely due to the induction of $\omega-3$ Des gene by low temperature.

\section{MOLECULAR SWITCH OF MICROORGANISMS THAT PRODUCE N-3 FATTY ACID AS MAJOR LIPIDS}

Many oleaginous microalgae can produce n-3 VLPUFAs and the $\Delta 6$ Des from several n-3 fatty acid producing organisms have been characterized biochemically Table 3, (Dunstan et al., 1992; Domergue et al., 2005; Petrie et al., 2010a; 2010b; Wagner et al., 2010; Ahmann et al., 2011). In general, the substrate preference of $\Delta 6$ Des correlates with the ratio of n-3/n- 6 fatty acids. Marine microalgae are one of the primary producers of $n-3$ fatty acids, such as EPA and DHA and the ratio of $n-3 / n-6$ fatty acids in these organisms are usually very high. In terms of the substrate specificities of the $\Delta 6$ Des in these organisms, as shown in Table 3, they usually prefer to use n-3 fatty acids ALA. For example, $\Delta 6$
Des from Ostreococcus lucimarinus showed strong preference for ALA, 39\% of fed ALA was converted to SDA, while only $6.6 \%$ of fed LA was converted to GLA. $\Delta 6$ Des from Micromona pusilla also shows strong preference for $n-3$ fatty acids, the conversion yield of ALA is ten times higher than that of LA.

These data suggests that the substrate preference of $\Delta 6$ Des play a major role in directing the flux of LA into n-3/n-6 fatty acid pathway. However, it is noteworthy that $\Delta 6$ Des from microalgae Phaeodactylum ricornutum, Glossomastix chrysoplasta and Thalassiosira pseudonana have no significant substrate preference (Table 4), but these organisms can still produce n-3 fatty acids as major PUFAs, indicating that an active $\omega-3$ Des gene is highly expressed in these organisms, although the $\omega-3$ Des from these organisms have not been characterized so far. Taken together, the n-3 fatty acid preference of $\Delta 6$ Des and the potential high-level expression of $\omega-3$ Des gene probably lead to the high production of $n-3$ fatty acids and thus high ratio of n-3/n- 6 fatty acids.

\section{POTENTIAL REGULATORY MECHANISM OF THE MOLECULAR SWITCH}

The molecular switch of n-6/n-3 PUFA production is controlled by the substrate preference of $\Delta 6$ Des and the activity of $\omega-3$ Des. Although many studies have been carried out to determine the substrate preference of heterogeneous expressed $\Delta 6$ Des, no structure-function studies have been achieved so far, not to mention how this substrate preference of $\Delta 6$ Des may be regulated by nutritional or environmental conditions.

The molecular mechanism for the sensing of lowtemperature and induced expression of desaturase gene in eukaryotic organisms is unknown, however it has been investigated in cyanobacteria and Bacillus subtilis (Suzuki and Murata, 2000; Aguilar et al., 2001) and well reviewed (Sakamoto and Murata, 2002; Shivaji and Prakash, 2010). It was suggested that the primary signal perceived by a bacterium when exposed to low-temperature is the rigidification of the membrane. This causes the activation of a membrane-associated sensor, which in turn, activates a cytosolic response regulator. Besides, this activated response regulator binds to the promoter of the desaturase and as a consequence the desaturase is induced. In cyanobacteria the Hik 33 (sensor)-Rer 26 (response regulator), while in Bacillus the DesK (sensor)-DesR (response regulator), the two component system for lowtemperature signaling has been identified (Suzuki and Murata, 2000; Aguilar et al., 2001). 
Table 1. Microorganisms that contain both $\Delta 6$ Des and $\omega-3$ Des

\begin{tabular}{|c|c|c|c|c|}
\hline \multirow{2}{*}{ Cyanobacteria } & \multirow{2}{*}{ Family } & Species & \multirow{2}{*}{$\begin{array}{l}\text { Main PUFAs }(\%) \\
\text { GLA: } 21 \\
\text { SDA: } 8\end{array}$} & References \\
\hline & & $\begin{array}{l}\text { Synechocystis } \\
\text { sp. PCC } 6803\end{array}$ & & $\begin{array}{l}\text { (Wada and Murata, 1990; } \\
\text { Reddy et al., 1993; } \\
\text { Sakamoto et al. 1994) }\end{array}$ \\
\hline \multirow[t]{3}{*}{ Yeast } & Saccharomycetaceae & Candida diddensiae & $\begin{array}{l}\text { ALA: } 5 \\
\text { SDA: } 1 \\
\text { GLA: } 10\end{array}$ & $\begin{array}{l}\text { (Rateldge, 1997) } \\
\text { (Shimizu et al., 1988; } \\
\text { Sakuradani } \text { et al., 2005) }\end{array}$ \\
\hline & \multirow[t]{2}{*}{ Mortierellaceae } & Mortierella elongate & $\begin{array}{l}\text { GLA: } 37 \\
\text { ARA: } 5 \\
\text { EPA: } 7 \\
\text { ARA: } 11^{\text {a }}\end{array}$ & (Bajpai et al., 1992) \\
\hline & & Pythium irregular & $\begin{array}{l}\text { EPA: } 14^{\mathrm{a}} \\
\text { ARA: } 10^{\mathrm{b}}\end{array}$ & (O'Brien et al., 1993; \\
\hline \multirow[t]{6}{*}{ Filamentous fungus } & \multirow[t]{2}{*}{ Pythiaceae } & Pythium ultimum & $\begin{array}{l}\text { EPA: } 25^{\mathrm{b}} \\
\text { ARA: } 15 \\
\text { EPA: } 12 \\
\text { GLA: } 2\end{array}$ & $\begin{array}{l}\text { Hong et al., 2002) } \\
\text { (Weete and Gandhi, 1992) }\end{array}$ \\
\hline & & Phytophthora infestans & $\begin{array}{l}\text { ARA: } 3 \\
\text { EPA: } 20 \\
\text { GLA: } 3 \\
\text { DGLA: } 7\end{array}$ & $\begin{array}{l}\text { (Larkin and Groves, 2003; } \\
\text { Sun } \text { et al., 2013) }\end{array}$ \\
\hline & Ancylistaceae & Conidiobolus obscures & $\begin{array}{l}\text { ARA: } 10 \\
\text { ETA: } 1 \\
\text { EPA: } 7\end{array}$ & (Tan et al., 2011) \\
\hline & \multirow[t]{2}{*}{ Saprolegniaceae } & Saprolegnia diclina & $\begin{array}{l}\text { ARA: } 10 \\
\text { EPA: } 20 \\
\text { SDA: } 21\end{array}$ & $\begin{array}{l}\text { (Gellerman and Schlenk, 1979; } \\
\text { Pereira } \text { et al., 2004) }\end{array}$ \\
\hline & & Micromonas pusilla & $\begin{array}{l}\text { EPA: }<1 \\
\text { DPA: }<1 \\
\text { DHA: } 9\end{array}$ & $\begin{array}{l}\text { (Dunstan et al., 1992; } \\
\text { Petrie et al., 2010b) }\end{array}$ \\
\hline & Mamiellaceae & Ostreococcus lucimarinus & DHA: 3 & $\begin{array}{l}\text { (Petrie et al., 2010a; } \\
\text { Ahmann } \text { et al., 2011) }\end{array}$ \\
\hline \multirow[t]{12}{*}{ Microalgae } & \multirow[t]{2}{*}{ Phaeodactylaceae } & \multirow[t]{2}{*}{ Phaeodactylum tricornutum } & $\begin{array}{l}\text { DHA: } 12 \\
\text { ETA: }<1 \\
\text { ARA: } 1\end{array}$ & $\begin{array}{l}\text { (Domergue et al., 2005; } \\
\text { Wagner } \text { et al., 2010) }\end{array}$ \\
\hline & & & $\begin{array}{l}\text { EPA: } 36 \\
\text { DHA: } 3 \\
\text { EPA: } 17 \\
\text { DHA: } 5\end{array}$ & $\begin{array}{l}\text { (Grima et al., 1996; } \\
\text { Domergue } \text { et al., 2002) } \\
\text { (Tonon et al., 2002; } \\
\text { Tonon } \text { et al., 2005) }\end{array}$ \\
\hline & \multirow[t]{2}{*}{ Pinguiochrysidaceae } & Glossomastix chrysoplasta & $\begin{array}{l}\text { ARA: } 6 \\
\text { EPA: } 39 \\
\text { DHA: } 9\end{array}$ & $\begin{array}{l}\text { (Kawachi et al., 2002; } \\
\text { Hsiao et al., 2007) }\end{array}$ \\
\hline & & Parietochloris incise & $\begin{array}{l}\text { ARA: } 57 \\
\text { EPA: }<1\end{array}$ & (Iskandarov et al., 2010) \\
\hline & \multirow[t]{3}{*}{ Chlorellaceae } & Chlorella minutissima & $\begin{array}{l}\text { ARA: } 3 \\
\text { EPA: } 45\end{array}$ & (Seto et al., 1984) \\
\hline & & Chlorella NKG042401 & $\begin{array}{l}\text { GLA: } 11 \\
\text { ALA: } 14 \\
\text { ARA: } 5 \\
\text { EPA: } 2\end{array}$ & (Hirano et al., 1990) \\
\hline & & Schizochytrium sp. & $\begin{array}{l}\text { DPA: }<1 \\
\text { DHA: } 6\end{array}$ & (Nagano et al., 2011) \\
\hline & \multirow[t]{2}{*}{ Thraustochytriaceae } & & $\begin{array}{l}\text { ARA: } 5 \\
\text { EPA: } 3\end{array}$ & \\
\hline & & Thraustochytrium sp. & $\begin{array}{l}\text { DPA: }<1 \\
\text { DHA: } 29 \\
\text { ARA: } 1\end{array}$ & (Nagano et al., 2011) \\
\hline & \multirow[t]{2}{*}{ Isochrysidaceae } & Isochrysis galbana & $\begin{array}{l}\text { EPA: } 25 \\
\text { DHA: } 11\end{array}$ & (Liu et al., 2013) \\
\hline & & Nannochloropsis oculata & $\begin{array}{l}\text { ARA: } 4 \\
\text { EPA: } 38\end{array}$ & $\begin{array}{l}\text { (Tonon et al., 2002) } \\
\text { (Tonon } \text { et al., 2002) }\end{array}$ \\
\hline & Monodopsidaceae & Nannochloropsis sp. & $\begin{array}{l}\text { ALA: } 2 \\
\text { ARA: } 5 \\
\text { EPA: } 28\end{array}$ & (Nitsan et al., 1999) \\
\hline
\end{tabular}


Table 2. $\Delta 6$ Des with substrate preference of LA

\begin{tabular}{|c|c|c|c|c|c|}
\hline \multirow[b]{2}{*}{ Organisms } & \multirow[b]{2}{*}{ Main PUFAs (\%) } & \multirow[b]{2}{*}{ n-3 FAs/n-6 FAs } & \multicolumn{2}{|c|}{$\begin{array}{l}\Delta 6 \text { Des substrate } \\
\text { conversion yield }{ }^{\S}(\%)\end{array}$} & \multirow[b]{2}{*}{ Reference } \\
\hline & & & LA & ALA & \\
\hline Mt. alpina $1 \mathrm{~S}-4$ & $\begin{array}{l}\text { ARA: } 48^{*} \\
\text { EPA: } 0^{*} \\
\text { GLA: } 10^{\dagger}\end{array}$ & & & & $\begin{array}{l}\text { (Shimizu et al., 1988; } \\
\text { Sakuradani and Shimizu, 2003) }\end{array}$ \\
\hline & $\begin{array}{l}\text { ARA: } 28^{\dagger} \\
\text { EPA: } 15^{\dagger}\end{array}$ & $\begin{array}{l}0^{\mathrm{a}} \\
<1^{\mathrm{b}}\end{array}$ & 47 & 30 & $\begin{array}{l}\text { (Zhu et al., 2002; } \\
\text { Liu et al., 2011) }\end{array}$ \\
\hline Mt. alpina $\mathrm{W} 15$ & $\begin{array}{l}\text { GLA: } 4 \\
\text { DGLA: } 3 \\
\text { AA: } 9\end{array}$ & 0 & 51 & 0 & \\
\hline
\end{tabular}

*Strain was cultivated at $28^{\circ} \mathrm{C}+$ Strain was cultivated at $12^{\circ} \mathrm{C} \S$ Substrate conversion yield was calculated as described previously (Sakuradani et al., 2005), Conversion yield $(\%)=100 \times$ ([product]/ [product + substrate]. $\Delta 6$ Desaturase gene from M. alpina $1 \mathrm{~S}-4$ was expressed in A. oryzae. $\Delta 6$ Des gene from M. alpina W15 was expressed in P. pastoris. The substrate preference was calculated based on its endogenous fatty acids production

Table 3. $\Delta 6$ Des with substrate preference of ALA

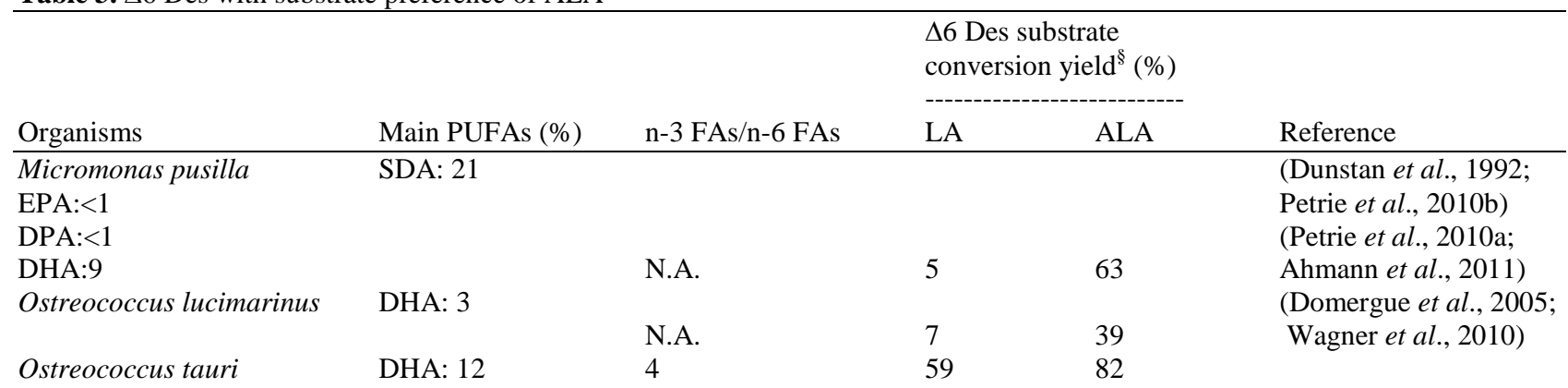

§Substrate conversion yield was calculated as described previously (Sakuradani et al., 2005), Conversion yield $(\%)=100 \times$ ([product]/ [product + substrate]. NA: Not Available. $\Delta 6$ Des genes in these organisms were expressed in S. cerevisiae and the substrate preference was studied by feeding the yeast with exogenous precursor fatty acids as substrates

Table 4. $\Delta 6$ Des with no significant substrate preference

\begin{tabular}{|c|c|c|c|c|c|}
\hline \multirow[b]{2}{*}{ Organism } & \multirow[b]{2}{*}{ Main PUFAs (\%) } & \multirow[b]{2}{*}{ n-3 FAs/n-6 FAs } & \multicolumn{2}{|c|}{$\begin{array}{l}\Delta 6 \text { Des substrate } \\
\text { conversion yield }^{\S}(\%)\end{array}$} & \multirow[b]{2}{*}{ Reference } \\
\hline & & & LA & ALA & \\
\hline Parietochloris incisa & $\begin{array}{l}\text { ARA: } 57 \\
\text { EPA: }<1\end{array}$ & & & & (Iskandarov et al., 2010) \\
\hline Synechocystis sp. PCC 6803 & $\begin{array}{l}\text { GLA: } 21 \\
\text { SDA: } 8\end{array}$ & $<1$ & 5 & 5 & $\begin{array}{l}\text { (Wada and Murata, 1990; } \\
\text { Reddy et al., 1993) }\end{array}$ \\
\hline Conidiobolus obscurus & $\begin{array}{l}\text { GLA: } 3 \\
\text { DGLA: } 7 \\
\text { ARA: } 10 \\
\text { ETA: } 1 \\
\text { EPA: } 7\end{array}$ & $<1$ & 68 & 57 & (Tan et al., 2011) \\
\hline Pythium irregulare & $\begin{array}{l}\text { ARA: } 11^{*} \\
\text { EPA: } 14^{*} \\
\text { ARA: } 10^{\dagger}\end{array}$ & $<1$ & 15 & 16 & $\begin{array}{l}\text { (O'Brien } \text { et al., 1993; } \\
\text { Hong } \text { et al., 2002) }\end{array}$ \\
\hline
\end{tabular}


Table 4. Continue

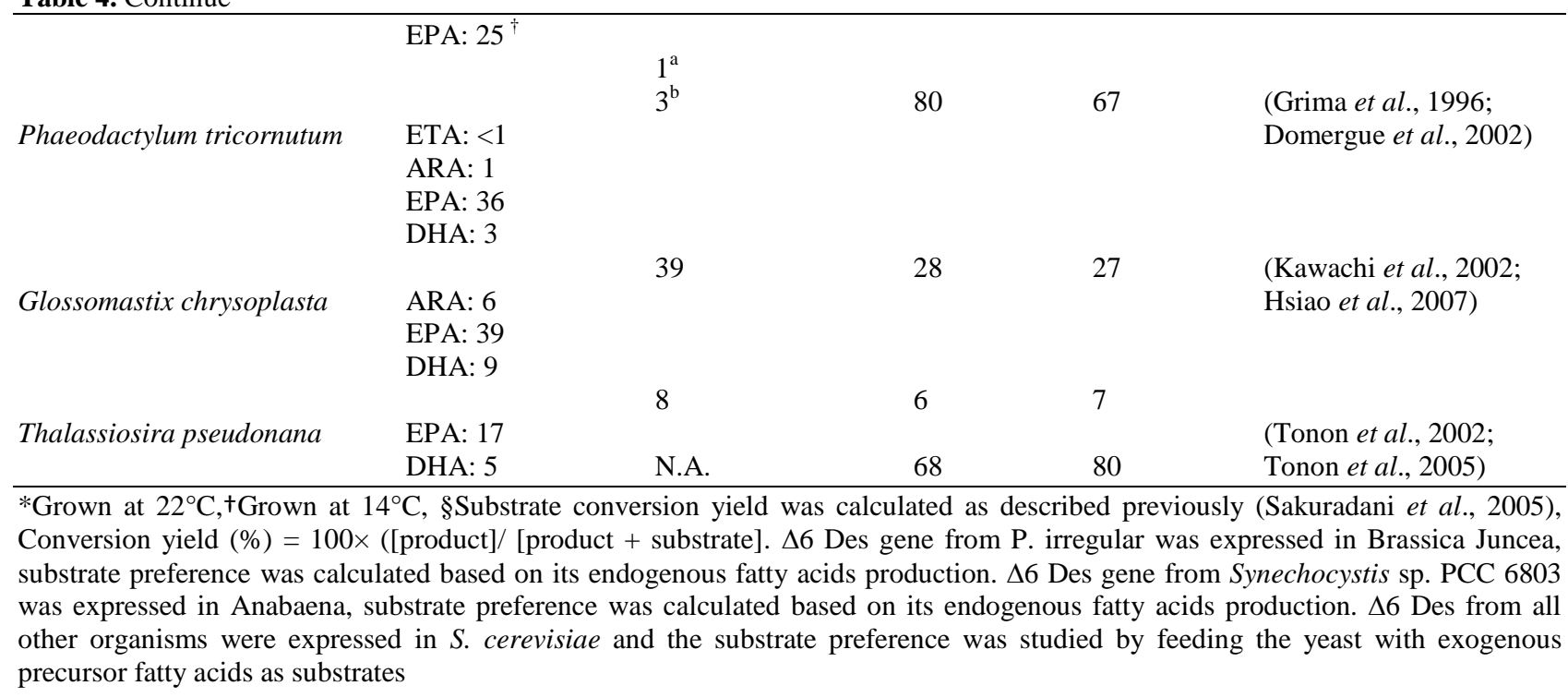

Table 5. $\omega-3$ Des from different species ${ }^{\mathrm{a}}$

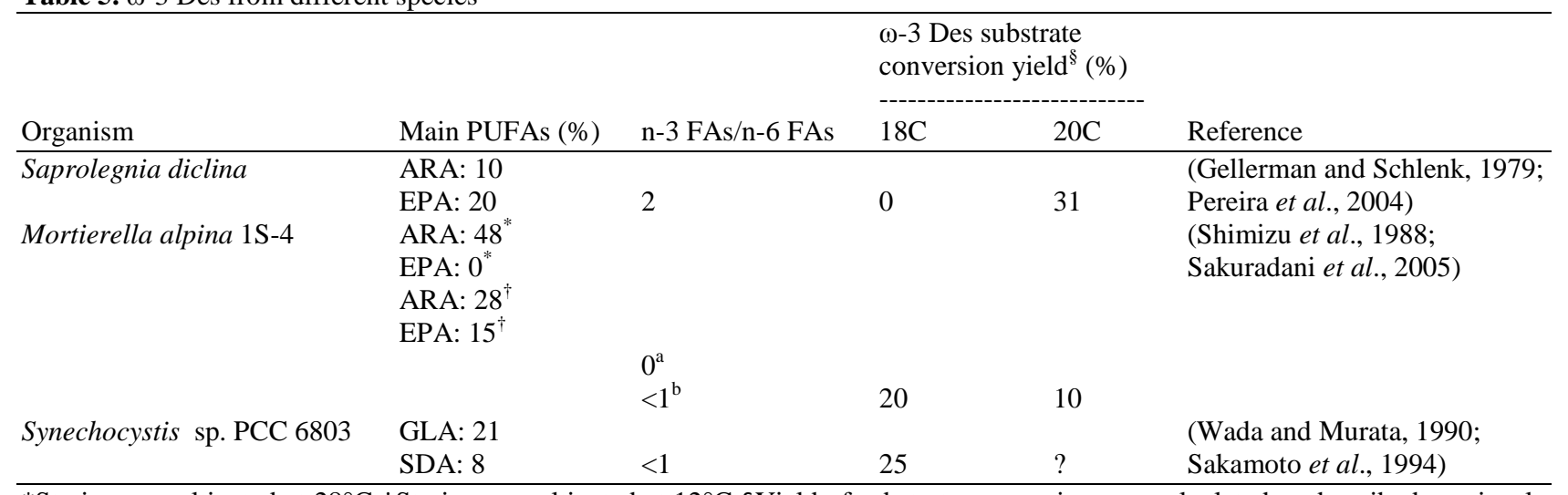

*Strain was cultivated at $28^{\circ} \mathrm{C} \dagger$ Strain was cultivated at $12^{\circ} \mathrm{C} \S$ Yield of substrate conversion was calculated as described previously (Sakuradani et al., 2005), Conversion yield $(\%)=100 \times$ ([product]/ [product + substrate]. $\omega-3$ Des gene from Synechocystis sp. PCC 6803 was expressed in Synechococcus sp. PCC 7942. $\omega-3$ Des genes from other organisms were expressed in S. cerevisiae, the substrate preference was studied by feeding the yeast with exogenous precursor fatty acids as substrates

\section{SUMMARY}

Most fungi, microalgae and some bacteria produce PUFAs through oxidative desaturation of fatty acids but only some of them can produce both GLA and ALA and their derived fatty acids, these organisms contain both $\Delta 6$ and $\omega-3$ Des. The substrate preference of $\Delta 6$ Des of microorganisms plays a major role in directing the metabolic flux of LA into either n- 6 or n-3 PUFAs. It produces n-6 or n-3 PUFAs as major product according to its substrate preference of n-6 or n-3 fatty acids. However when the substrate preference of $\Delta 6$ Des for
LA or ALA is comparable, then the activity of $\omega-3$ Des, which is controlled by its genetic background, but also regulated by environmental stimuli such as temperature, determines the metabolic flux of LA into n-6 or n-3 fatty acids. When the activity of $\omega-3$ Des is very low, the microorganism produces $n-6$ fatty acids as major lipids; when the activity of $\omega-3$ Des is very high, then it produces n-3 fatty acids as major lipids and at certain activity level, it may produce equal amount of n-6 and n3 fatty acids. The substrate preference of $\Delta 6$ Des is controlled by its protein structure which is primary determined by the amino acid sequence of the protein, 
whether and how this substrate preference may be regulated by other nutritional or environmental conditions is, so far, not clear. The molecular mechanism of low temperature induced expression of fatty acid desaturase in bacteria has been investigated, the two component system for the sensing of the low temperature signal and the transduction of this signal to the induction of the expression of fatty acid desaturase has been identified in some bacteria. However the mechanism for the low temperature induced expression of $\omega-3$ Des in eukaryotic microorganisms is completely unknown. Research into this area should be exciting and provide insights to the understanding of the biochemistry of n6/n-3 PUFA biosynthesis in oleaginous microorganisms.

\section{ACKNOWLEDGEMENT}

This study was supported by the National Natural Science Foundation of China (31271812, 81071685), the National High Technology Research and Development Program of China (863 Program 2012AA022105C) and Strategic Mérieux Research Grant. We thank Professor Colin Ratledge for his constructive criticism of the manuscript.

\section{REFERENCES}

Abd Elrazak, A., A. Ward and J. Glassey, 2013. Polyunsaturated fatty acid production by marine bacteria. Bioproc. Biosyst. Eng., 36: 1641-1652. DOI: 10.1007/s00449-013-0936-0

Aguilar, P.S., A.M. Hernandez-Arriaga, L.E. Cybulski, A.C. Erazo and D. De Mendoza et al., 2001. Molecular basis of thermosensing: a two-component signal transduction thermometer in Bacillus subtilis. EMBO J., 20: 1681-1691. DOI: 10.1093/emboj/20.7.1681

Ahmann, K., M. Heilmann and I. Feussner, 2011. Identification of a $\Delta 4$-desaturase from the microalga Ostreococcus lucimarinus. Eur. J. Lipid Sci. Technol., 113: 832-840. DOI: 10.1002/ejlt.201100069

Ando, A., Y. Sumida, H. Negoro, D.A. Suroto and S. Shimizu et al., 2009. Establishment of Agrobacterium tumefaciens-mediated transformation of an oleaginous fungus, Mortierella alpina $1 \mathrm{~S}-4$ and its application for eicosapentaenoic acid producer breeding. Applic. Environ. Microbiol., 75: 55295535. DOI: 10.1128/AEM.00648-09
Bajpai, P., P. Bajpai and O. Ward, 1992. Optimisation of culture conditions for production of eicosapentaenoic acid by Mortierella elongate NRRL 5513. J. Ind. Microbiol., 9: 11-17. DOI: 10.1007/BF01576363

Candela, C.G., L.M.B. López and V.L. Kohen, 2011. Importance of a balanced omega 6/omega 3 ratio for the maintenance of health. Nutritional recommendations. Importancia del equilibrio del índice omega-6/omega-3 en el mantenimiento de un buen estado de salud recomendaciones. Nutr. Hosp., 26: 323-329.

Domergue, F., A. Abbadi, U. Zähringer, H. Moreau and E. Heinz et al., 2005. In vivo characterization of the first acyl-CoA $\Delta 6$-desaturase from a member of the plant kingdom, the microalga Ostreococcus tauri. Biochem. J., 389: 483-483. DOI: 10.1042/BJ20050111

Domergue, F., J. Lerchl, U. Zähringer and E. Heinz, 2002. Cloning and functional characterization of Phaeodactylum tricornutum front-end desaturases involved in eicosapentaenoic acid biosynthesis. Eur. J. Biochem., 269: 4105-4113. DOI: 10.1046/j.14321033.2002.03104.x

Dunstan, G.A., J.K. Volkman, S.W. Jeffrey and S.M. Barrett, 1992. Biochemical composition of microalgae from the green algal classes Chlorophyceae and Prasinophyceae. 2. Lipid classes and fatty acids. J. Exp. Mar. Biol. Ecol., 161: 115134. DOI: 1016/0022-0981(92)90193-E

Dyal, S.D. and S.S. Narine, 2005. Implications for the use of Mortierella fungi in the industrial production of essential fatty acids. Food Res. Int., 38: 445-467. DOI: 10.1016/j.foodres.2004.11.002

Gellerman, J.L. and H. Schlenk, 1979. Methyl-directed desaturation of arachidonic to eicosapentaenoic acid in the fungus, Saprolegnia parasitica. Biochimica et Biophysica Acta (BBA)-Lipids Lipid Metabolism, 573: 23-30. DOI: 10.1016/0005-2760(79)90169-3

Grima, E.M., A.R. Medina, A.G. Giménez and M.J.I. González, 1996. Gram-scale purification of Eicosapentaenoic Acid (EPA, 20: 5n-3) from wet Phaeodactylum tricornutum UTEX 640 biomass. J. Applic. Phycol., 8: 359-367. DOI: 10.1007/BF02178579

Gunstone, F.D., 1992. Gammar linolenic acid-occurrence and physical and chemical properties. Prog. Lipid Res., 31: 145-161. DOI: 1016/0163-7827(92)900076 
Harris, W., 2006. The omega-6/omega-3 ratio and cardiovascular disease risk: Uses and abuses. Current Atherosclerosis Reports, 8: 453-459. DOI: 10.1007/s11883-006-0019-7

Hirano, M., H. Mori, Y. Miura, N. Matsunaga and T. Matsunaga et al., 1990. $\gamma$-linolenic acid production by microalgae. Applic. Biochem. Biotechnol., 24: 183-191. DOI: 10.1007/BF02920244

Hong, H., N. Datla, D.W. Reed, P.S. Covello and X. Qiu et al., 2002. High-level production of $\gamma$-linolenic acid in brassica juncea using a $\Delta 6$ desaturase from pythium irregulare. Plant Physiol., 129: 354-362. DOI: 10.1104/pp.001495

Hsiao, T.Y., B. Holmes and H.W. Blanch, 2007. Identification and functional analysis of a delta-6 desaturase from the marine microalga Glossomastix chrysoplasta. Mar. Biotechnol. NY, 9: 154-165. DOI: $10.1007 / \mathrm{s} 10126-006-6075-8$

Iskandarov, U., I. Khozin-Goldberg and Z. Cohen, 2010. Identification and Characterization of $\Delta 12, \Delta 6$ and $\Delta 5$ Desaturases from the Green Microalga Parietochloris incisa. Lipids, 45: 519-530. DOI: 10.1007/s11745-010-3421-4

Kawachi, M., I. Inouye, D. Honda, C.J. O'Kelly and R.A. Andersen, 2002. The pinguiophyceae classis nova, a new class of photosynthetic stramenopiles whose members produce large amounts of omega-3 fatty acids. Phycol. Res., 50: 31-47. DOI: 10.1111/j.1440-1835.2002.tb00134.x

Kennedy, M.J., S.L. Reader and R.J. Davies, 1993. Fatty acid production characteristics of fungi with particular emphasis on gamma linolenic acid production. Biotechnol. Bioeng., 42: 625-634. DOI: 10.1002/bit.260420511

Larkin, R.P. and C.L. Groves, 2003. Identification and Characterization of Isolates of Phytophthora infestans Using Fatty Acid Methyl Ester (FAME) Profiles. Plant Dis., 87: 1233-1243. DOI: 10.1094/PDIS.2003.87.10.1233

Lenihan-Geels, G., K. Bishop and L. Ferguson, 2013. Alternative sources of omega-3 fats: Can we find a sustainable substitute for fish. Nutrients, 5: 13011315. DOI: $10.3390 /$ nu5041301

Liu, J., D. Li, Y. Yin, H. Wang and L. Yu et al., 2011. $\Delta 6-$ Desaturase from Mortierella alpina: CDNA cloning, expression and phylogenetic analysis. Biotechnol. Lett., 33: 1985-1991. DOI: 10.1007/s10529-0110650-4
Liu, J., M. Sommerfeld and Q. Hu, 2013. Screening and characterization of Isochrysis strains and optimization of culture conditions for docosahexaenoic acid production. Applic. Microbiol. Biotechnol., 97: 4785-4798. DOI: 10.1007/s00253-013-4749-5

Metz, J.G., P. Roessler, D. Facciotti, C. Levering and J. Browse et al., 2001. Production of polyunsaturated fatty acids by polyketide synthases in both prokaryotes and eukaryotes. Science, 293: 290-293. DOI: 10.1126/science.1059593

Murata, N. and H. Wada, 1995. Acyl-lipid desaturases and their importance in the tolerance and acclimatization to cold of cyanobacteria. Biochem. J., 308: 1-8. PMID: 7755550.

Nagano, N., K. Sakaguchi, Y. Taoka, Y. Okita and M. Hayashi et al., 2011. Detection of genes involved in fatty acid elongation and desaturation in thraustochytrid marine eukaryotes. J. Oleo Sci., 60: 475-481. DOI: 10.5650/jos.60.475

Nguyen, H.M., S., Cuiné, A. Beyly-Adriano, B. Légeret and Y. Li-Beisson et al., 2013. The green microalga chlamydomonas reinhardtii has a single $\omega$-3 fatty acid desaturase that localizes to the chloroplast and impacts both plastidic and extraplastidic membrane lipids. Plant Physiol., 163: 914-928. DOI: 10.1104/pp.113.223941

Nitsan, Z., S. Mokady and A. Sukenik, 1999. Enrichment of poultry products with $\omega 3$ fatty acids by dietary supplementation with the alga nannochloropsis and mantur oil. J. Agric. Food Chem., 47: 5127-5132. DOI: 10.1021/jf981361p

O’Brien, D.J., M.J. Kurantz and R. Kwoczak, 1993. Production of eicosapentaenoic acid by the filamentous fungus Pythium irregulare. Applic. Microbiol. Biotechnol., 40: 211-214. DOI: 10.1007/BF00170368

Pereira, S.L., A.E. Leonard and P. Mukerji, 2003. Recent advances in the study of fatty acid desaturases from animals and lower eukaryotes. Prostaglandins Leukotrienes Essential Fatty Acids, 68: 97-106. DOI: 10.1016/S0952-3278(02)00259-4

Pereira, S.L., Y.S. Huang, E.G. Bobik, A.J. Kinney and P. Mukerji et al., 2004. A novel omega3-fatty acid desaturase involved in the biosynthesis of eicosapentaenoic acid. Biochem. J., 378: 665-671. DOI: $10.1042 / \mathrm{BJ} 20031319$ 
Petrie, J.R., Q. Liu, A.M. Mackenzie, P. Shrestha and S.P. Singh et al., 2010a. Isolation and characterisation of a high-efficiency desaturase and elongases from microalgae for transgenic LC-PUFA production. Mar. Biotechnol., 12: 430-438. DOI: 10.1007/s10126-009-9230-1

Petrie, J.R., P. Shrestha, M.P. Mansour, P.D. Nichols and S.P. Singh et al., 2010b. Metabolic engineering of omega-3 long-chain polyunsaturated fatty acids in plants using an acyl-CoA $\Delta 6$-desaturase with $\omega 3$ preference from the marine microalga Micromonas pusilla. Metab. Eng., 12: 233-240. DOI: 10.1016/j.ymben.2009.12.001

Rateldge, C., 1997. Microbial Lipids. In: Biotechnology: Products of Secondary Metabolism, Rehm, H.J., R. Reed, A. Pulher, H. Kleinkauf and H. Dohren (Eds.), VCH, Weinheim, Germany, pp: 133-197.

Reddy, A.S., M.L. Nuccio, L.M. Gross and T.L. Thomas, 1993. Isolation of a $\Delta 6$-desaturase gene from the cyanobacterium Synechocystis sp. strain PCC 6803 by gain-of-function expression in Anabaena sp. strain PCC 7120. Plant Mol. Biol., 22: 293-300. DOI: $10.1007 / \mathrm{BF} 00014936$

Sakamoto, T. and N. Murata, 2002. Regulation of the desaturation of fatty acids and its role in tolerance to cold and salt stress. Curr. Opin. Microbiol., 5: 206210. DOI: $10.1016 / \mathrm{S} 1369-5274(02) 00306-5$

Sakamoto, T., D.A. Los, S. Higashi, H. Wada and N. Murata et al., 1994. Cloning of $\omega 3$ desaturase from cyanobacteria and its use in altering the degree of membrane-lipid unsaturation. Plant Mol. Biol., 26: 249-263. DOI: 10.1007/BF00039536

Sakuradani, E. and S. Shimizu, 2003. Gene cloning and functional analysis of a second $\Delta 6$-fatty acid desaturase from an arachidonic acid-producing Mortierella fungus. Biosci. Biotechnol. Biochem., 67: 704-711. DOI: 10.1271/bbb.67.704

Sakuradani, E., T. Abe, K. Iguchi and S. Shimizu, 2005. A novel fungal omega3-desaturase with wide substrate specificity from arachidonic acidproducing Mortierella alpina 1S-4. Applic. Microbiol. Biotechnol., 66: 648-654. DOI: 10.1007/s00253-004-1760-x

Sayanova, O., J.A. Napier and P.R. Shewry, 1999. $\Delta 6-$ Unsaturated fatty acids in species and tissues of the Primulaceae. Phytochemistry, 52: 419-422. DOI: 10.1016/S0031-9422(99)00256-3
Sayanova, O., R. Haslam, M. Venegas-Calerón and J. Napier, 2006. Identification of Primula "front-end" desaturases with distinct n-6 or n-3 substrate preferences. Planta, 224: 1269-1277. DOI: 10.1007/s00425-006-0306-0

Sayanova, O.V., F. Beaudoin, L.V. Michaelson, P.R. Shewry and J.A. Napier et al., 2003. Identification of Primula fatty acid $\Delta 6$-desaturases with n-3 substrate preferences. FEBS Lett., 542: 100-104. DOI: 10.1016/S0014-5793(03)00358-2

Scott, D.D., K. Srirama and B.S. Carani, 2007. Omega-3 fatty acids for nutrition and medicine: Considering microalgae oil as a vegetarian source of EPA and DHA. Curr. Diabetes Rev., 3: 198-203. DOI: 10.2174/157339907781368968

Seto, A., H.L. Wang and C.W. Hesseltine, 1984. Culture conditions affect eicosapentaenoic acid content of Chlorella minutissima. J. Am. Oil Chem. Soc., 61: 892-894. DOI: 10.1007/BF02542159

Shi, Y., L. An, X. Li, C. Huang and G. Chen et al., 2011. The octadecanoid signaling pathway participates in the chilling-induced transcription of $\omega-3$ fatty acid desaturases in Arabidopsis. Plant Physiol. Biochem., 49: 208-215. DOI: 10.1016/j.plaphy.2010.11.013

Shimizu, S., Y. Shinmen, H. Kawashima, K. Akimoto and H. Yamada et al., 1988. Fungal mycelia as a novel source of eicosapentaenoic acid: Activation of enzyme(s) involved in eicosapentaenoic acid production at low temperature. Biochem. Biophys. Res. Commun., 150: 335-341. DOI: 10.1016/0006291X(88)90525-6

Shimizu, K., K. Suhara, M. Ikumo, M.I. Eremets and K. Amaya, 1998. Superconductivity in oxygen. Nature, 393: 767-769. DOI: 10.1038/31656

Shivaji, S. and J.S. Prakash, 2010. How do bacteria sense and respond to low temperature. Arch. Microbiol., 192: 85-95. DOI: 10.1007/s00203-009-0539-y

Sun, Q., J. Liu, Q. Zhang, X. Qing and B. Qi et al., 2013. Characterization of three novel desaturases involved in the delta-6 desaturation pathways for polyunsaturated fatty acid biosynthesis from Phytophthora infestans. Applic. Microbiol. Biotechnol., 97: 7689-7697. DOI: 10.1007/s00253012-4613-z

Suzuki, I. and N. Murata, 2000. Perception and transduction of low-temperature signals to induce desaturation of fatty acids. Biochem. Soc. Trans., 28: 628-630. DOI: 10.1042/BST0280628 
Takemura, M., T. Hamada, H. Kida and K. Ohyama, 2012. Cold-Induced accumulation of $\omega-3$ polyunsaturated fatty acid in a liverwort, Marchantia polymorpha L. Biosci Biotechnol Biochem., 76: 785-790. DOI: 10.1271/bbb.110915

Tan, L., D. Meesapyodsuk and X. Qiu, 2011. Molecular analysis of $\Delta 6$ desaturase and $\Delta 6$ elongase from Conidiobolus obscurus in the biosynthesis of eicosatetraenoic acid, a $\omega 3$ fatty acid with nutraceutical potentials. Applic. Microbiol. Biotechnol., 90: 591-601. DOI: 10.1007/s00253-010-3060-y

Tonon, T., D. Harvey, T.R. Larson and I.A. Graham, 2002. Long chain polyunsaturated fatty acid production and partitioning to triacylglycerols in four microalgae. Phytochemistry, 61: 15-24. DOI: 10.1016/S0031-9422(02)00201-7

Tonon, T., O. Sayanova, L.V. Michaelson, R. Qing and I.A. Graham et al., 2005. Fatty acid desaturases from the microalga Thalassiosira pseudonana. FEBS J., 272: 3401-3412. DOI: 10.1111/j.17424658.2005.04755.x

Wada, H. and N. Murata, 1990. Temperature-induced changes in the fatty acid composition of the cyanobacterium, Synechocystis PCC6803. Plant Physiol., 92: 1062-1062. DOI: 10.1104/pp.92.4.1062
Wagner, M., K. Hoppe, T. Czabany, M. Heilmann and G. Daum et al., 2010. Identification and characterization of an acyl-CoA: Diacylglycerol Acyltransferase 2 (DGAT2) gene from the microalga O. tauri. Plant Physiol. Biochem., 48: 407-416. DOI: 10.1016/j.plaphy.2010.03.008

Wang, L., W. Chen, Y. Feng, Y. Ren and I.M. Berquin et al., 2011. Genome characterization of the oleaginous fungus Mortierella alpina. PloS One, 6: 2831928319. DOI: 10.1371/journal.pone.0028319

Weete, J.D. and S.R. Gandhi, 1992. Industrial Applications of Single Cell Oils. In: Enhancement of C20 Polyunsaturated Fatty Acid Production in Pythium Ultimum, Kyle, D.J. and C. Ratledge (Eds.), AOCS Publishing, ISBN-10: 978-0-93531539-4, pp: 300.

Zhang, P., S. Liu, B. Cong, G. Wu and X. Huang et al., 2011. A novel omega-3 fatty acid desaturase involved in acclimation processes of polar condition from Antarctic ice algae Chlamydomonas sp. ICE-L. Mar. Biotechnol., 13: 393-401. DOI: 10.1007/s10126-010-9309-8

Zhu, M., P.P. Zhou and L.J. Yu, 2002. Extraction of lipids from Mortierella alpina and enrichment of arachidonic acid from the fungal lipids. Bioresour. Technol., 84: 93-95. DOI: 10.1016/S09608524(02)00028-7 